\title{
Harold E. Kleinert - A tribute to a pioneer
}

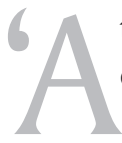

teacher never dies, He always lives in the minds of his students'.

To a student of hand surgery, the mention of the name Kleinert is associated with the advances he helped to make in flexor tendon repair and rehabilitation. It is normal that a surgeon is recognised by the contributions he/she made for the growth of the specialty. With Dr. Kleinert, personally, I think it is different. I think his greatest contribution to hand surgery is the creation of the fellowship program at Lousiville. It became truly international with surgeons from 65 countries being trained. The Kleinert fellowship staffed the whole world with hand surgeons who pushed the boundaries of care in their respective countries. If you take the history of the various national associations of hand surgery, at least one former Kleinert fellow would have adorned the mantle of the Presidency of the national association.

I was fortunate to spend a year as a fellow at the Kleinert Institute (1989-1990) [Figure 1]. I cherish and value the memories of moments spent together with the staff and co fellows, as much as the hand surgery techniques that I learnt at Louisville. Good teachers are truly inspirational. I wish to put in words some events which left a lasting impression in my mind.

Louisville has a system of the attending staff (consultant) staying in house on the days of call. On one of the Dr. Kleinert's on-call days, as his fellow, I received a case of a woman in the emergency room who had been flown in from Virginia with a fingertip amputation through the nail. Although she had come for replantation, I thought it would be too tough to replant and she would do as

\begin{tabular}{|l|l|}
\hline \multicolumn{2}{|c|}{ Access this article online } \\
\hline Quick Response Code: & Website: \\
\hline & www.ijps.org \\
\hline & \\
\hline
\end{tabular}

well with an advancement flap. Hence, I explained her towards that and took her up to the theatre. She also agreed to that option. Just as we were draping the hand for surgery, Dr. Kleinert came into the theatre. It was a little beyond midnight. He looked over our shoulders and in his characteristic way said, 'What are you young guys doing now?'’ To that my colleague said, 'Harold, this woman has been flown all the way from Virginia for replantation. Raja has talked to her and she has agreed for a triangular flap, which I think is a sensible option'. To that, Dr Kleinert said, 'May be, but is that what she wanted? Did you explore the amputated part for the possibility of replant before going for this?' We had not. We had decided that she will have a triangular flap anyway. Harold then said, 'Why do not you try?'. We did, found the vessels and she went on to have a successful replant. She was one of the most delighted patients. Then, Harold told us,'This woman has been flown all the way from Virginia, thinking that Harold will put it

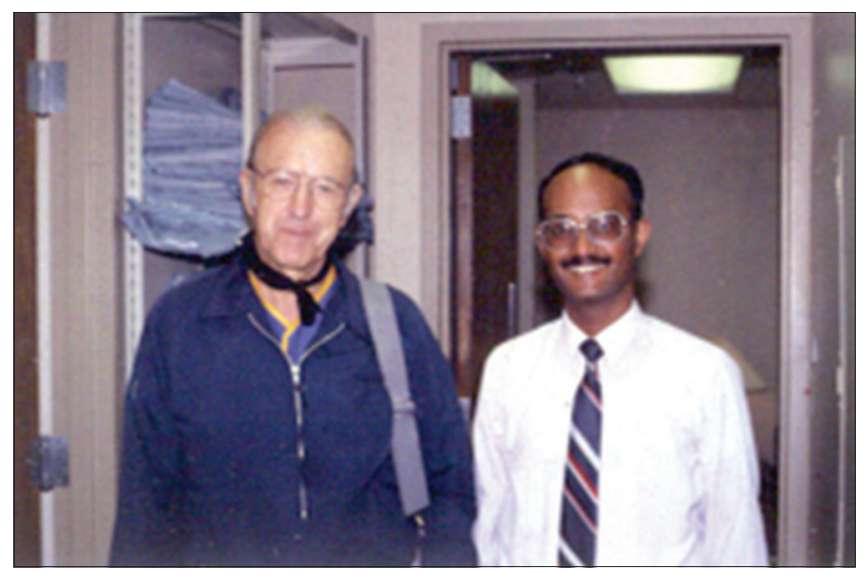

Figure 1: The author with Dr. Kleinert in 1989 during his training in Louisville

This is an open access article distributed under the terms of the Creative Commons Attribution-NonCommercial-ShareAlike 3.0 License, which allows others to remix, tweak, and build upon the work non-commercially, as long as the author is credited and the new creations are licensed under the identical terms.

For reprints contact: reprints@medknow.com

How to cite this article: Sabapathy SR. Harold E. Kleinert - A tribute to a pioneer. Indian J Plast Surg 2016;49:140-3. 
back. You did not even try. If we had not tried replanting such injuries when I was in your age, you may not have chosen to come here. At all times, it is good to try'. That night was one of the defining moments of my training. On many occasions, when faced with difficult situations, before giving up of choosing an easier but not the best option, I think of that night, that voice of Kleinert over my shoulders and say to myself, 'Why do not you try?'.

As an Indian trainee going to the US in the eighties, everything was interesting (from cars to shopping malls!). The fellowship provided an opportunity for overseas trainees to come over and get a limited registration of the Kentucky Medical council for practice without going through the formalities of examinations [Figure 2]. Harold and team were all younger and worked really hard. The enthusiasm in the air was infective. Every morning, - Monday to Saturday, we used to have academic sessions starting at $630 \mathrm{am}$ for an hour. Harold and Tsu Min Tsai were the members who put in the most attendance. At the end of many discussions, Harold used to speak from the depth of his experience, recollecting interesting historical facts and linking them to the present day. It was fascinating. Then, I understood that it is just not enough, if you are a good hand surgeon, you need to put all this to make an institution. One day when I was talking about this that we need to reproduce this model in India, I spoke of the possible challenges. I was particularly referring to funding. Harold simply said, "If you love hand surgery, keep on doing good hand surgeries, everything will take care of itself'. Harold sometimes can say things which could have deep meaning. It is 25 years since we started in 1991, and nothing could be more true than those words. Now I am convinced, 'If you love your work, keep on doing good to the patients, everything will

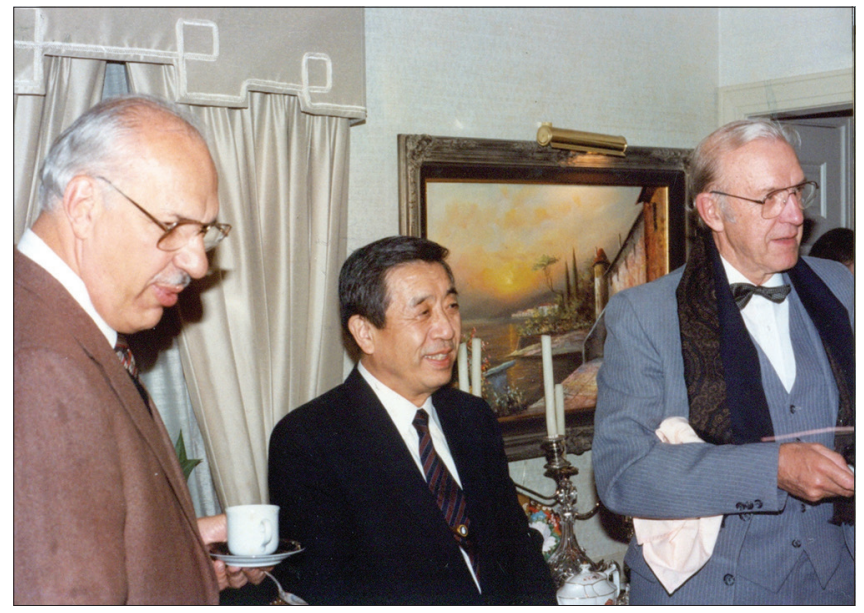

Figure 2: Louisville was the most 'visited place', for hand surgeons. Picture taken during Prof. Tajima's visit. Dr. Kutz, Kleinert's first partner, is also in the picture take care of itself'. On the contrary, I have also realised that if you skip that point (loving what you do, keep on doing good to the patients), nothing can take care of you.

While on the topic of building institutions, I have to mention two more lessons learnt. Harold's list of requirements for creating a great hand injury centre was simple three requirements. They are as follows:

1. Availabiity

2. Affability

3. Abillity (in the same order of importance).

He explained to me that no matter how good you are, if you are not available when the patient comes injured, nothing matters. $100 \%$ availability of skilled person is the first requirement. Next, it is important to be nice to the patient. Harold was a patient's man. He could talk about so many things before coming to the problem in question. But, I have found that he finds the solution better than a person who just goes straight into the clinical problem. No matter how good you are, it is important to be nice. Third, he put ability, which is important, but without the first two does not help to create the trust of patients. I truly believed in this. When we started our centre, when there were invitations to join other hospitals or do some sessions, the voice of Dr. Kleinert emphasising availability always came to my mind. Though we did not have a busy practice to start with, it helped to stay put in our own centre, and as we evolved, the 'availability' factor became our strength. To the 3As, we added affordability to suit the Indian conditions.

We used to have an operating session in Indiana and the trip with him was more interesting than the surgeries we did there. One day I asked him as to how he chose

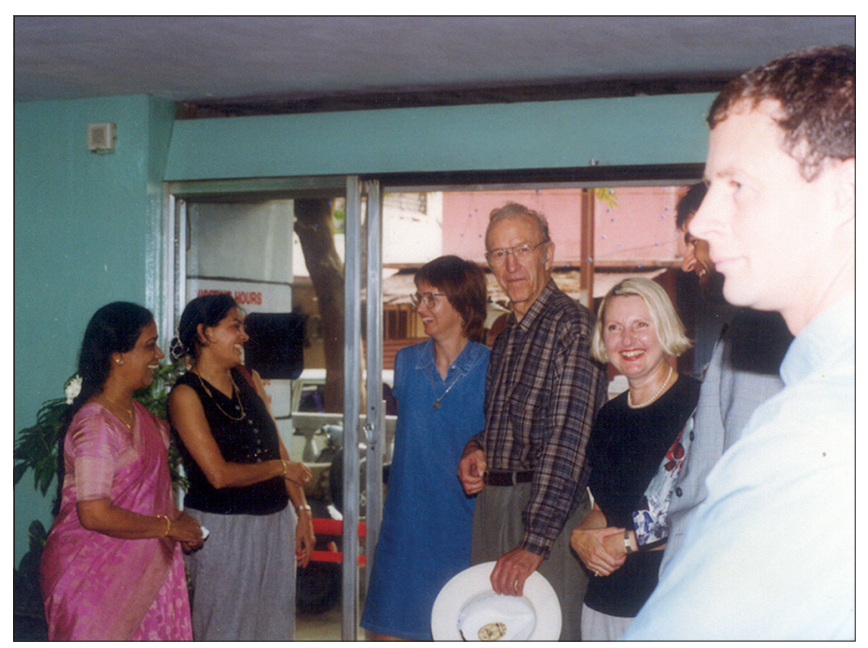

Figure 3: Dr. Kleinert and Mrs. Sharon Kleinert arrving at Ganga Hospital, in 1997, for participation in the ISSH 1997

Indian Journal of Plastic Surgery May-August 2016 Vol 49 Issue 2 
people while building a team. He said, 'When I choose a fellow, I do not mind a monkey, as long he is an interested monkey. However, when you choose a permanent staff or partner, it is important that more than his/her skills, the persons' acceptance by the entire team, the colleagues, the office staff, the nurses and physios all matter.' I think this again is a sage's advice. He also said that though everyone understands that it is important, mistakes can happen easily. This is very true again. Only time can tell if the decisions are correct and I realise that determines the fate of many institutions.

When I joined the fellowship on the first day at lunch time, he came over to some of us who had joined that day and said, 'Shall I get you lunch?' and took us to the lounge for a good lunch. I was very impressed at his hospitality. Only later did I realise that the lunch is free for all the staff of the hospital and that was one of his usual ways of introduction to the new fellows.

Finally, about his interest in coming to work. On an evening, during the annual ASSH meeting, there is a Kleinert reunion of former fellows. Many times, we used to be told that Harold is retiring and it is good to come to the reunion. When the next year comes, we used to hear the same again. During one such reunion, a former fellow asked him, 'Harold, when are you really going to retire?' Harold without batting an eyelid replied, 'I do not retire, God retires people'. A legend he was, ultimately he retired. He has left indelible marks in the history of hand surgery through the people he trained and for the windows of opportunity he threw open to the young minds.

We started our work in 1991 and soon picked up volume. When we had the opportunity to host the ISSH meeting in 1997 at Coimbatore, we invited Harold Kleinert to be the chief guest [Figure 3]. Amit Gupta had by that time joined Lousiville and he was instrumental in making the visit happen. I am grateful to him. We had Kleinert, Tsu Min Tsai, Amit Gupta, MariaSiemionow (USA), Peter Burge, Andy Carr (UK), MilomerNinkovic (Austria), Pathmanathan (Malaysia), Lam ChuanTeoh (Singapore) and Antony Burger (Australia) as visiting faculties. All of them came with their families. His coming helped us to get 220 registrations which was a record at that time. The inauguration was on August $15^{\text {th }}, 1997$, and it was the $50^{\text {th }}$ year of India's independence. Kleinert gave a great speech during the inauguration. The whole atmosphere was electrifying. He brought in great value to the meeting by being there in all the sessions to the end of the day and contributing to the discussions very freely. In a way that was a watershed year for the growth of Indian hand surgery due to the exposure it had with people whose opinion mattered. Amit had organised a good pre-congress tour and we organised a good post-congress tour. They left with a great impression of India. In April, this year, I had been to Louisville to pay homage to Dr. Acland, another great person who had helped to the growth of Indian hand surgery and microsurgery, I also paid my respects at the cemetery of

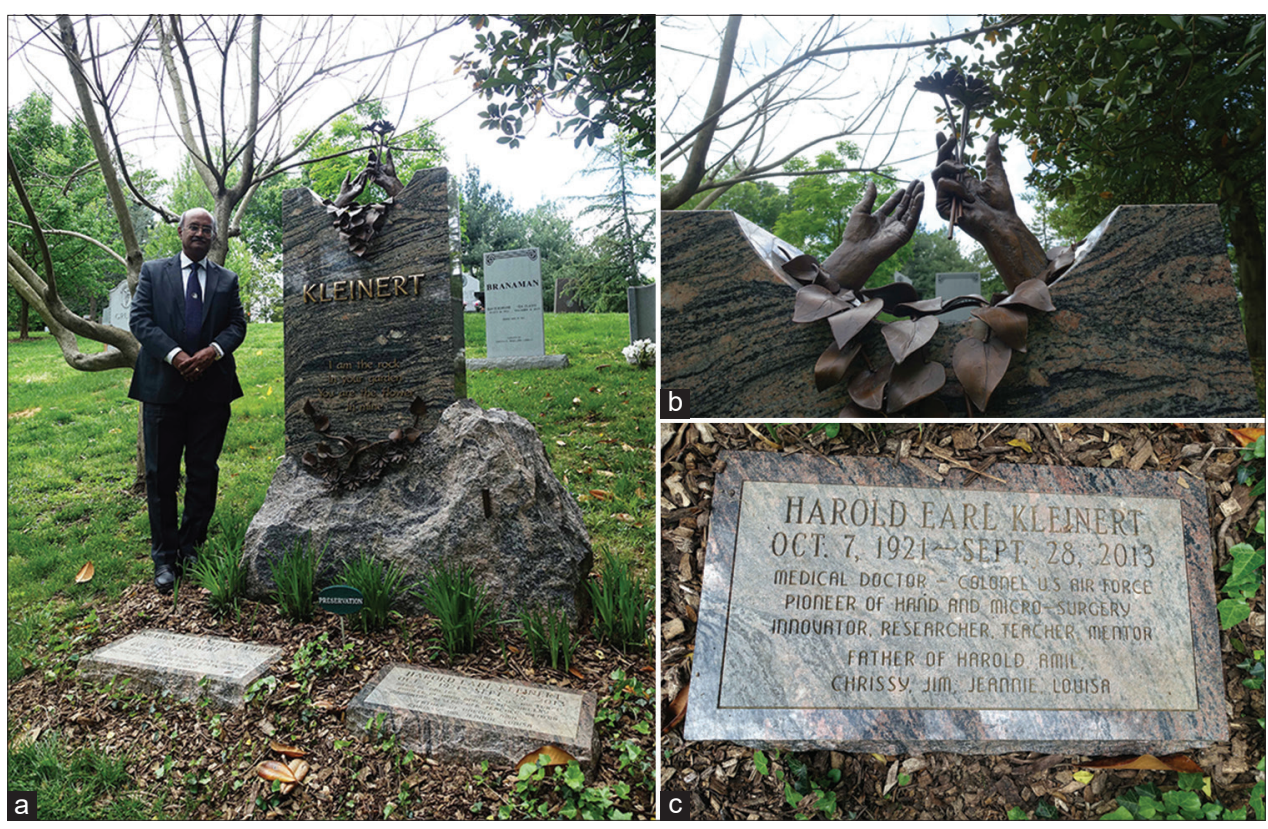

Figure 4a-c: The author paying respect at the cemetery and the inscription on the tombstone 
Harold Kleinert [Figures 4a-c]. In the remembrance dinner, Mrs. Sharan Kleinert spoke of the great memories of India they had during their visit and how Dr. Kleinert and Dr. Acland both loved India. She said that the memories are so strong that she suggested to Mrs. Acland that they must visit India again. The 1997 meeting inspired us to institute the first oration in ISSH in honour of Prof. Venkataswami, and in the subsequent year, we instituted the oration in honour of Prof. BB Joshi.

To recognise the contribution of Dr. Kleinert to the growth of international hand surgery, the International Federation of Societies for Surgery of the Hand (IFSSH) has instituted the Kleinert Professorship, wherein it will fund the visit of a professor to visit another country for teaching and training and address their national association meeting. A fitting tribute to a surgeon who truly belonged to the world.

\section{Financial support and sponsorship}

Nil.

\section{Conflicts of interest}

There are no conflicts of interest.

S. Raja Sabapathy

Chairman, Division of Plastic Surgery, Hand and Reconstructive Microsurgery, Ganga Hospital, Coimbaotre, India

Address for correspondence: Dr. S. Raja Sabapathy, Ganga Hospital, 313, Mettupalayam Road, Coimbatore - 641043 Tamil Nadu, India. E-mail: rajahand@gmail.com 